\title{
Prevalence of Alcohol Consumption and Factors Influencing Alcohol Use Among the Youth in Tokorni-Hohoe, Volta Region of Ghana
}

\author{
Emmanuel Osei-Bonsu" ${ }^{2}$, Prince Kubi Appiah ${ }^{1, ~}$, Ishmael D. Norman ${ }^{3}$, Geoffrey Adebayo Asalu ${ }^{1}$, \\ Margaret Kweku², Seth Yao Ahiabor ${ }^{2}$, Wisdom Kwami Takramah ${ }^{2}$, Abdulai Bonchel Duut ${ }^{4}$, \\ George Edward Ntow ${ }^{2}$, Stephen Boadu ${ }^{2}$ \\ ${ }^{1}$ Department of Family and Community Health, School of Public Health, University of Health and Allied Sciences, Ho, Ghana \\ ${ }^{2}$ Department of Epidemiology and Biostatistics, School of Public Health, University of Health and Allied Sciences, Ho, Ghana \\ ${ }^{3}$ Department of Health Policy, Planning and Management, School of Public Health, University of Health and Allied Sciences, Ho, Ghana \\ ${ }^{4}$ Department of Social Work, University of Ghana, Legon, Accra, Ghana
}

Email address:

appiahkubiprince23@yahoo.com (P. K. Appiah)

${ }^{*}$ Corresponding author

To cite this article:

Emmanuel Osei-Bonsu, Prince Kubi Appiah, Ishmael D. Norman, Geoffrey Adebayo Asalu, Margaret Kweku, Seth Yao Ahiabor, Wisdom Kwami Takramah, Abdulai Bonchel Duut, George Edward Ntow, Stephen Boadu. Prevalence of Alcohol Consumption and Factors Influencing Alcohol Use Among the Youth in Tokorni-Hohoe, Volta Region of Ghana. Science Journal of Public Health. Vol. 5, No. 3, 2017, pp. 205-214. doi: 10.11648/j.sjph.20170503.18

Received: December 3, 2016; Accepted: December 14, 2016; Published: March 27, 2017

\begin{abstract}
Background: Alcohol use still remains a great public health concern. However, the youth are the higher risk group in terms of alcohol consumption and its associate complications. Alcohol consumption among the youth is on the rise and Ghana cannot be exempted due to easy accessibility and availability of alcoholic beverages to the youth. According to Ghana Demographic and Health survey, alcohol consumption is highest among young people between the ages of 15-39 years than other age group; however, little information on alcohol consumption has made the problem unknown, limiting appropriate measures to control its use. This study measured the prevalence of alcohol consumption and associated factors among the youth in Tokorni-Hohoe. Methods: The study employed cross sectional study using quantitative method to sample 316 respondents. Random and systematic sampling techniques were used to sample respondents. Structured questionnaire was used to collect relevant information from respondents. The analysis was performed using StataSE 12. Results: The prevalence of alcohol consumption among the youth is $43 \%$. Both males and females engage in alcohol use but more males were found to use alcohol than females. Alcohol consumption was highest among the age group of 20-25 years. The major factors influencing the use are peer influence $(30.8 \%)$ and advertisement $(20.3 \%)$. All the socio-demographic characteristics except religion $(p=0.011)$ and occupation $(p=0.001)$ were found not to be strongly associated with alcohol consumption. Reasons given by the youth for consuming alcohol are to have fun and to stimulate their appetite for food. Conclusions: Alcohol use is highly prevalent among the youth in Tokorni-Hohoe and therefore interventions to prevent its use should be more focus on the youth because of their vulnerability. Advertisement on alcohol use must be control by the appropriate institutions.
\end{abstract}

Keywords: Alcohol, Consumption, Use, Youth, Tokorni-Hohoe

\section{Introduction}

Alcohol use among the youth forms one of the most important public health challenges despite strenuous efforts made to contain it [1]. Alcohol is considered as one of the initial substances that are used among young people before they progress to the use of more dangerous substances such as marijuana and cocaine [2]. With modernization in the world market and increase in advertisement, harmful drinks that were not easily accessible to the youth are now of higher 
consumption rate than expected [3]. In recent times, because of the promotion, competition and popularity of alcoholic products, most alcoholic beverages are now cheaper as compared to other soft drinks [4]. Due to this multiplicity, most young people engage in heavy drinking at younger ages than in the past.

Alcohol comes in the form of beer, wine, spirit and other alcoholic beverages. Beer include malt beer, wine from grapes, spirits from distilled beverages and other fermented beverages made from cereals such as maize, millet and sorghum [4].

Introduction to alcohol use at early age in life is another disturbing trend in youth drinking. A survey conducted in United States of America indicated that the average age of initiation to alcohol use among young people is 15 years [5]. Another survey conducted in Thai indicated that $79.7 \%$ of Thai current drinkers are over 15 years old and was reported that the youth initiate to alcohol drinking between the ages of 15-24 years [6]. In Ghana, a study conducted among second cycle and out of school youth on substance use revealed that average age for first use of substance was between 14-19 years and the highest use was between the ages of 16-23 years. In addition, substances that are mostly used by the youth in Ghana include alcohol, cigarette, cannabis and heroine [7].

Data from Ghana Demographic and Health Survey indicated that the use of alcohol is prevalent among the youth between the ages of 15-34 years in Ghana with Volta Region recording the highest prevalence among males which constitutes $42 \%$, and among females, the highest prevalence of alcohol consumption was in Upper West Region with prevalent rate of $37 \%$ [8]. However, there is little control on the sale and consumption of alcohol among the youth in Ghana, and for this reason people in their youthful age can walk into any drinking bar to buy and consume alcohol [9]. A study conducted in a senior high school in Accra, at a mean age of 17 years found that the prevalent rate of lifetime alcohol consumption was $25.1 \%$ among lifetime users; whiles $42 \%$ were currently alcohol consumers [10].

In Africa, the rate of alcohol consumption is not different from the rest of the world because alcohol and other illicit drugs are easily accessible to the youth [11]. An empirical review of literature has demonstrated that a substantial proportion of youth in Sub-Saharan Africa have ever consumed alcohol or are currently consuming alcohol [10]. For instance, a study conducted in Uganda indicated that the country was having the highest annual consumption of pure alcohol in litres among the youth in the world [12]. Also, [13] reported in their study that one out of every three Zambian adolescents were consuming or have ever consumed alcohol.

Globally, alcohol consumption among the youth is of great concern. A worldwide survey on Alcohol and Health assessed a five year trend on alcohol consumption among the youth between the ages of 18-25 years in 82 countries and revealed that, there was $80 \%$ increase in consumption, $11 \%$ decrease in consumption, $6 \%$ stable consumption, while $12 \%$ showed inconclusive trends in consumption [14]. Again, [15] reports indicated that about 15.3 million youth between the ages of 15 to 29 years had drug disorders and 320,000 people of same age group die yearly from alcohol and drug related use, accounting for $9 \%$ of all deaths globally.

National surveys among adolescents, college students, and other young adults in the United State of America showed that youth have higher rates of alcohol intake, as well as higher rates of dangerous drinking practices such as binge drinking and daily drinking [16]. Also, a national survey conducted in Thai among the youth revealed that alcohol consumption has increased from $21.6 \%$ in 2001 , to $23.5 \%$ in 2004 and to $23.7 \%$ in 2006 [6]. This indicates that globally alcohol consumption among the youth is on the rise; therefore demands urgent control measures and interventions.

The effects that usually follow alcohol use on the youth has remained a topical issue as well as a worry to parents, schools, governments and the society as a whole. Furthermore, [17] indicated that, future manpower and development of every country's economy lies on the physical and mental health of its youth. However, alcohol consumption for instance still remains major risk behaviour among the youth leading to both physical and mental health complications including deaths [1]. Most chronic and injuryrelated conditions can be attributed to excessive alcohol consumption. These include but not limited to alcohol dependence; liver cirrhosis, cancers, depression and other medical conditions [18].

Moreover, alcohol has been identified as a contributor to traumatic outcomes that either kills or disables the consumer at a relatively younger age, thereby leading to loss of many years of life to death or disability [19]. In addition, [20] further indicated in his study that the high rate of death among the youth in Nigeria is related to unhealthy lifestyles of which the use of alcohol cannot be excluded. In spite of all these problems, the use of alcohol remains unconcerned and to date is of low priority to policy makers [21]. It is therefore imperative for all countries including Ghana to adopt appropriate strategies and interventions in fighting against any physical, psychological and socio-medical problems affecting the youth due to alcohol use.

The use of alcohol varies from one location to the other [20]. In the light of this, the study was conducted in TokorniHohoe to determine the prevalence of alcohol use and associated factors among the youth.

\section{Materials and Methods}

\subsection{Study Site}

Hohoe municipality has a total land surface area of 1,172 $\mathrm{km}^{2}$ which constitutes about $5.6 \%$ of the Regional and $0.05 \%$ of the National land surface areas. It is situated within longitude $0^{\circ} 15^{\prime} \mathrm{E}$ and $0^{\circ} 45^{\prime} \mathrm{E}$ and latitude $6^{\circ} 45^{\prime} \mathrm{N}$ and $7^{\circ}$ $15^{\prime} \mathrm{N}$ and lies nearly in the middle-belt of the Volta Region of Ghana with an estimated population of 188,963 and a growth rate of 2.4. 
Tokorni-Hohoe is one of the sub-communities located almost at the centre of Hohoe Township having a population of 3,914 based on the 2010 population census, with a growth rate of $2.5 \%$. The population of the youth in Tokorni-Hohoe is about 1,488 . Hohoe Township is where most travellers who are in search of job relocate making Tokorni-Hohoe one of the busiest communities in the town. The community was chosen because many and most prominent drinking bars in Hohoe Township are clustered, making alcoholic beverages easily accessible to the youth. Furthermore, the kind of entertainment provided by these drinking bars attract most people especially the youth to have fun in those places and in the process they tend to drink alcohol. This is making alcoholism becoming a serious issue among the youth in this community. The major occupation in the community is mainly petty trading. However, others engage in agricultural activities such as cultivation of Cocoa, Cassava, Rice and various vegetables notably Kontomire, Pepper and Okro. Poultry (chicken) is the leading animal reared in the municipality.

Hohoe Township has a hospital with a research centre, a private clinic, a health centre, and Reproductive and Child Health) unit with an Adolescent Health Corner. It also has four (4) tertiary institutions; a Midwifery Training School, a Public University offering courses in public health, two colleges of education, and a number of first and second cycle schools.

\subsection{Study Population}

Participants in the study were youths between the ages of 15-35 years. Data was collected from only those who agreed and signed informed consent form. However, individuals who have not stayed in the municipality for the past 3 months before the day of the study were also excluded from the study, as well as Non-Ghanaians and Health professionals even if they have stayed in the municipality for the required period.

\subsection{Study Design}

A descriptive cross sectional study using quantitative method was employed to determine the prevalence of alcohol consumption and the associated factors among the youth in the municipality between February and April, 2016.

\subsection{Sample Size}

Three Hundred and Sixteen (316) participants were involved, this was determined using the formula: $n=z^{2} x p$ $(q) \div d^{2}[22]$, Where $n$ is the Sample size to be determined, $\mathrm{z}$ is the $\mathrm{z}$-score (reliability coefficient) of 1.96 at $95 \%$ confidence level, $\mathrm{p}$ is the estimated proportion of an attribute that was present in the population (prevalence of alcohol consumption $0.25)$ [7], $\mathrm{d}$ is the desired level of precision $5 \%(0.05)$, and $\mathrm{q}$ is $1-p(0.75)$. For a $10 \%$ non-response rate of 288 , the sample size was upwardly adjusted and rounded to 316 participants. This sample size ensured, with probability of $95 \%$ that, the estimated prevalence fell within $\pm 5 \%$ of the true population prevalence.

\subsection{Sampling Method}

Multi-stage sampling method was used to select participants. A list of all the 986 houses in Tokorni-Hohoe was obtained from physical planning department in the Hohoe Municipal Assembly. Simple random sampling technique was used to select the first house and systematic sampling was then used to select every $3^{\text {rd }}$ house until all the 316 houses were selected. In houses where there were more than one household, simple random sampling was used to select one. This was done by balloting YES or NO and the household that picks YES was chosen for the study. In households where there were more eligible participants, again simple random sampling was used to select one respondent. This was also done through balloting YES OR NO, individuals who picks YES was chosen for the study.

\subsection{Data Collection}

A semi-structured questionnaire, pen and paper were used to obtained data from study participants on alcohol consumption and related factors through self-administration. Participants' ages were assessed using their Birth Certificates. Where certificates were not available, events calendar were used to determine their age.

\subsection{Ethical Issues}

The study conformed to the required ethical guidelines regarding the use of human subjects, and was approved by the Ethical Review Committee of the Ghana Health Services, Research and Development Division, Accra with protocol number GHS-ERC 08/02/16. Participation in the study was voluntary, and consent and assent was sought from the participants and their guardians.

\subsection{Data Analysis}

Data was entered using EPI Data version 3.1 Software and then exported to StataSE for analysis. Questions and responses were coded into numeric form for data entry. Descriptive statistics including mean, mode, percentages, and frequencies was calculated and presented in graphs and tables for quantitative variables. Beyond descriptive statistics, cross-tabulation using chi square was also used to determine the association between dependent and independent variables. The strength of the association was explored using logistic regression by computing odds ratio at $95 \%$ confidence interval, and a $p$-value $<0.05$ was considered as statistically.

\section{Results}

\subsection{Background Characteristics of Respondents}

A total of 316 respondents between the ages of 15-35 were involved in the study with a response rate of $100 \%$. Most $66.7 \%$ (211) of the respondents were males while the 
remaining 33.3\% (105) were females. The mean age of the respondents was 23 years with standard deviation of 4.6. Almost half $46 \%$ (146) of the respondents were within the age group of $20-25$, followed by $15-19$ age group $28.8 \%$ (91), 26-30 age group $17.41 \%$ (55) and 31-35 age group with $7.59 \%$ (24) respectively. Majority $31.3 \%$ (99) of the respondents were either in secondary school or had completed and only $8.54 \%$ (27) of the respondents had no formal education. Only $20 \%$ (63) of the participants were married and the remaining $80 \%$ (253) were not married. More than three-fourth $(76.3 \%)$ of the respondents were Christians, followed by Traditional African Worshipers $(13.6 \%)$ and Moslems (10.13\%) respectively. As high as $52.9 \%$ (167) of the respondents do not have any job doing. Out of the 167 participants, 35.1\% (111) were students and $17.72 \%$ (56) were unemployed. Respondents who were employed constituted 47.1\% (149) (Table 1).

Table 1. Socio-demographic Characteristics.

\begin{tabular}{lll}
\hline VARIABLES & FREQUENCY (316) & PERCENTAGE \\
\hline Sex & & \\
Male & 211 & 66.7 \\
Female & 105 & 33.3 \\
Age (years) & & \\
$15-19$ & 91 & 28.8 \\
20 - 25 & 146 & 46.2 \\
$26-30$ & 55 & 17.4 \\
31 - 35 & 24 & 7.59 \\
Education level & & \\
No education & 27 & 8.5 \\
Primary & 40 & 12.7 \\
Middle/JHS & 89 & 28.2 \\
Secondary & 99 & 31.3 \\
Tertiary & 61 & 19.3 \\
Marital status & & \\
Single & 253 & 80.1 \\
Married & 63 & 19.9 \\
Religion & & \\
Christian & 241 & 76.3 \\
Muslim & 43 & 10.1 \\
Traditionalist & 32 & 13.6 \\
OCCUPATION & & 17.7 \\
Unemployed & 56 & 19.0 \\
Trader & 60 & 12.4 \\
Artisan & 50 & \\
Student & 111 & \\
Others* & 39 & \\
\hline & & \\
Oters inc & & \\
\hline
\end{tabular}

*Others include Teachers, Health workers, Pastor, Farmers, Drivers, Security officer, Electrician, and Banker.

\subsection{Youths Currently Consuming Alcohol}

As high as $43.4 \%$ of the youths in Tokorni-Hohoe community are currently consuming alcoholic beverages, however, almost $70 \%$ of the youth had once in their lifetime ever consumed alcohol (Figure 1).

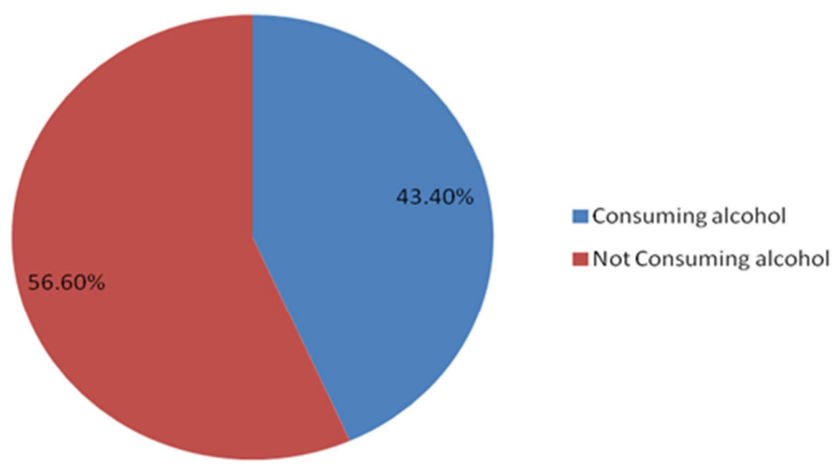

Figure 1. Youths currently consuming alcohol in the community.

\subsection{Alcohol Consumption and Background Characteristics}

More $101(73.7 \%)$ males consume alcohol than females 36 $(26.2 \%)$. However, sex specific analysis indicated that out of the 211 male participants, $47.9 \%$ are currently consuming alcohol while $34.3 \%$ out of the 105 female participants are also consuming alcohol currently. Approximately, $45 \%$ of the respondents who are currently consuming alcohol are among the age group of $20-25$ years and the least (11\%) among the age group of $30-35$ years. Out of the $43 \%$ (137) of the respondents who are currently consuming alcohol, $86 \%$ (118) had some level of education while $13 \%$ (19) had no education. Again, out of the 137 participants who are currently consuming alcohol, 72.9\% (100) were not married whiles $27 \%$ (37) were married. More than half $54.74 \%(75)$ of current alcohol consumers were employed whiles $45.26 \%$ (62) was among artisans (Table 2).

Table 2. Alcohol consumption and background characteristics in TokorniHohoe community.

\begin{tabular}{|c|c|c|}
\hline VARIABLES & FREQUENCY (N=137) & PERCENTAGE (5\%) \\
\hline \multicolumn{3}{|l|}{ Sex } \\
\hline Male & 101 & 73.7 \\
\hline Female & 36 & 26.3 \\
\hline \multicolumn{3}{|l|}{ Age (years) } \\
\hline $15-19$ & 29 & 21.2 \\
\hline $20-25$ & 62 & 45.3 \\
\hline $26-30$ & 31 & 22.6 \\
\hline $31-35$ & 15 & 10.9 \\
\hline \multicolumn{3}{|l|}{ Education level } \\
\hline No education & 19 & 13.9 \\
\hline Primary & 19 & 13.9 \\
\hline Middle/JSS & 39 & 28.4 \\
\hline Secondary & 31 & 22.6 \\
\hline Tertiary & 29 & 21.2 \\
\hline \multicolumn{3}{|l|}{ Marital status } \\
\hline Unmarried & 100 & 73.0 \\
\hline Married & 37 & 27.0 \\
\hline \multicolumn{3}{|l|}{ Religion } \\
\hline Christian & 105 & 76.6 \\
\hline Muslim & 28 & 20.4 \\
\hline Traditionalist & 4 & 3.0 \\
\hline \multicolumn{3}{|l|}{ Occupation } \\
\hline Unemployed & 62 & 45.3 \\
\hline Employed & 75 & 54.7 \\
\hline
\end{tabular}




\subsection{Frequency of Alcohol Consumption Among Youth}

The study also show that $16 \%$ of the youth in the

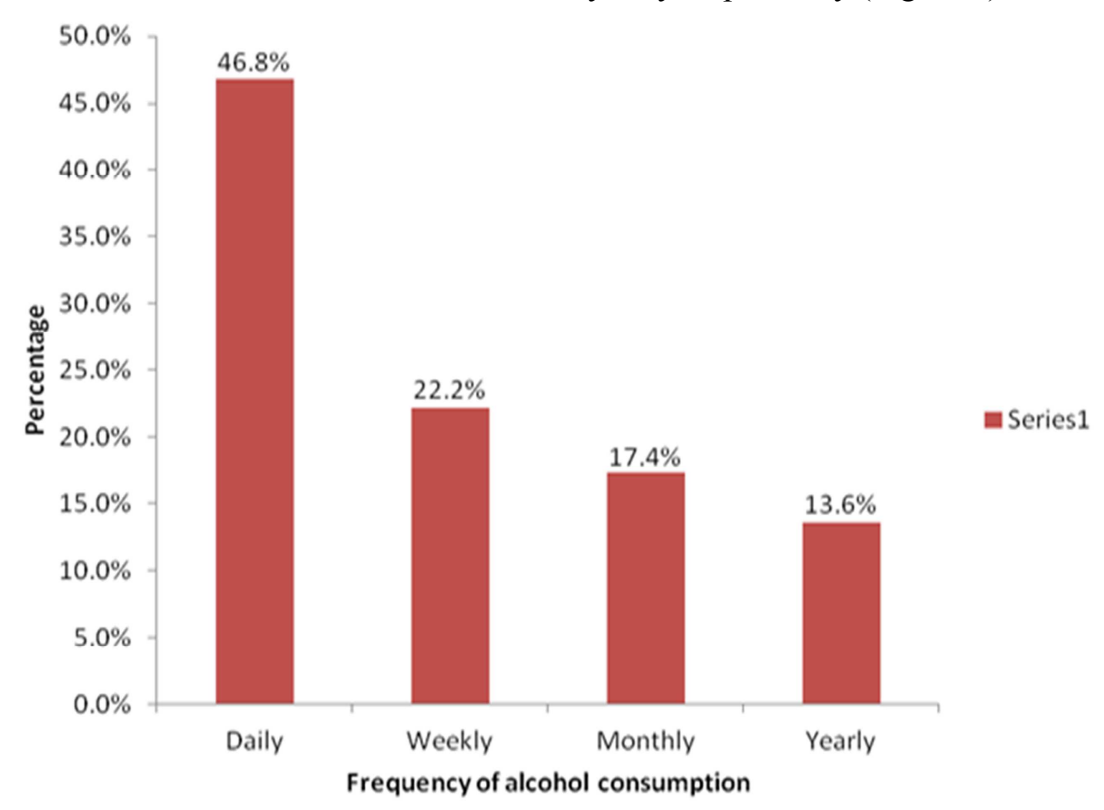

Figure 2. Frequency of alcohol consumption among youths in Tokorni-Hohoe community. community consume alcohol on daily basis, while $22.1 \%$, $17.41 \%$ and $13.6 \%$ consumed alcohol weekly, monthly and yearly respectively (Figure 2).

\subsection{Types of Alcohol Consume by the Youth}

The study indicated that alcoholic beverage mostly consumed by the youth in Tokorni-Hohoe was beer (34\%), followed by wine (31\%), 'spirit' constituted $21 \%$ while $14 \%$ of the respondents also do not have choice but consume all the alcoholic beverages (Figure 3).

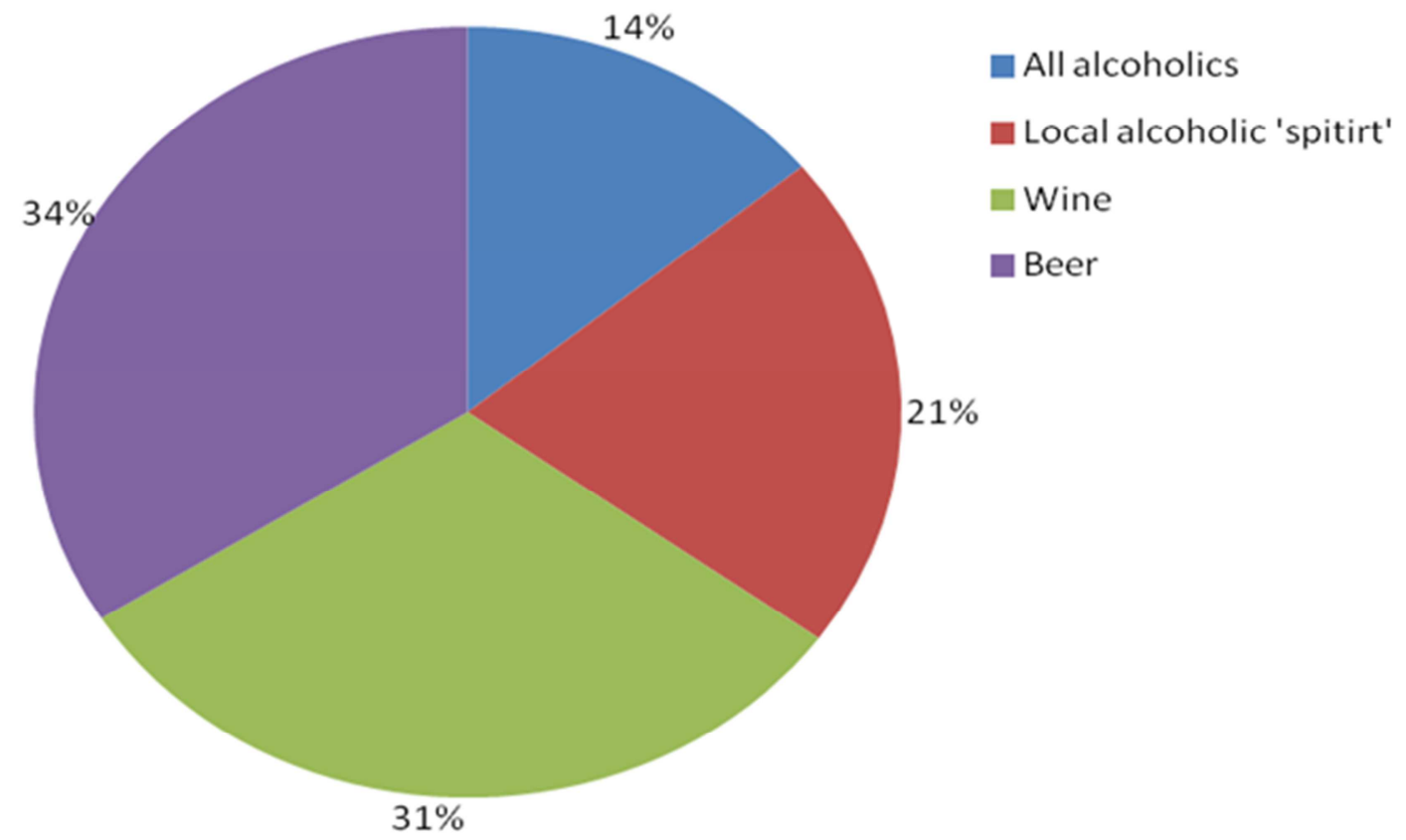

Figure 3. Types of alcoholic beverage consumed by youth in Tokorni-Hohoe community.

\subsection{Factor Contributing to Alcohol Consumption Among the Youth}

Almost one-third $(30.8 \%)$ of the youth are into alcohol consumption due to peer influence, $20.3 \%$ also attributed alcohol consumption to advertisement, $12.7 \%$ were based on easy availability and accessibility, $12.2 \%$ on social networking, 9.3\% also attributed alcohol consumption to parental influence whiles $14.7 \%$ attributed it to curiosity (Figure 4). 


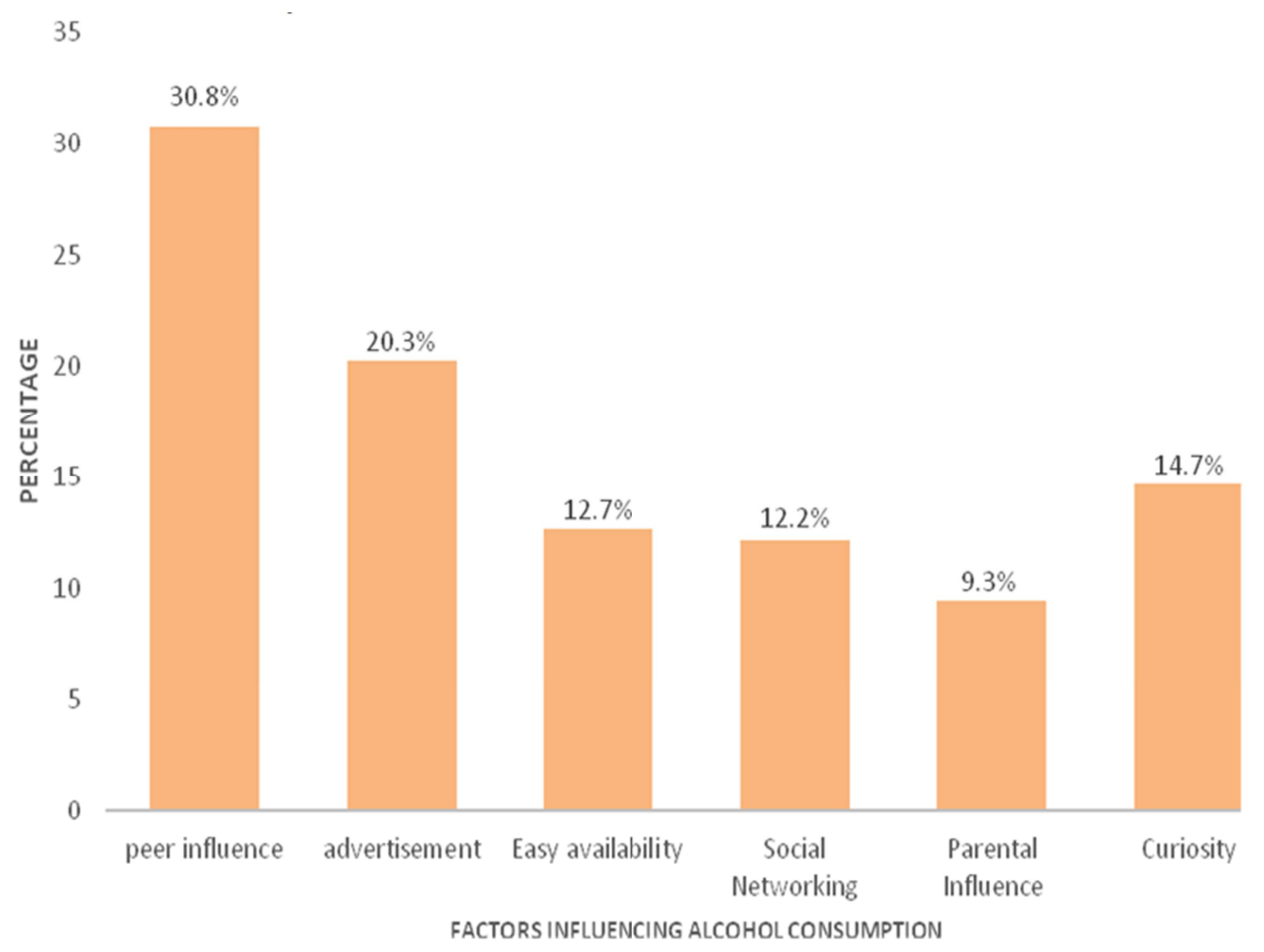

Figure 4. Factors influencing alcohol consumption among the youth in the community.

\subsection{Reasons for Alcohol Consumption Among the Youth}

There are several reasons why the youth in the community consume alcohol. Majority (28.7\%) consumed alcohol to have fun, followed by appetite for food (24\%), relaxation (14.4\%), coping with stress $(12.8 \%)$, sexual enhancement (11.9\%), imitate role model $(8 \%)$, and unemployment $(0.2 \%)$ as reason for alcohol consumption (Figure 5).

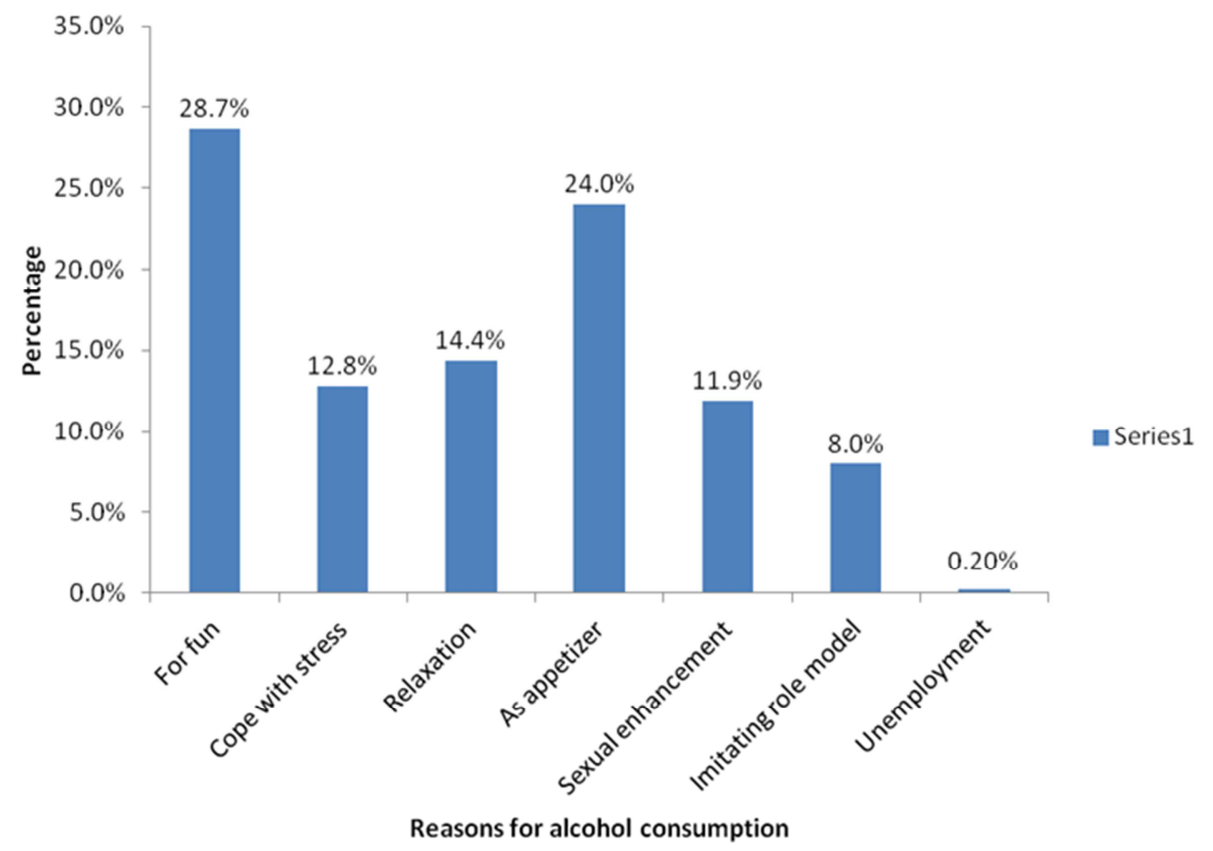

Figure 5. Reasons for alcohol consumption among youth in the community.

\subsection{Associations Between Alcohol Consumption and the Background Characteristics}

There is significant associations between alcohol consumption and sex $(\mathrm{p}=0.02)$, age $(\mathrm{p}=0.01)$, level of education $(\mathrm{p}=0.03)$, religion $(\mathrm{p}=0.02)$, and occupation $(\mathrm{p}<0.001)$. To further explore the strength of associations, multiple logistic regression analysis was done to confirm the 
association between alcohol consumption and independent variables. The analysis confirmed strong association between alcohol consumption and religion $(\mathrm{p}=0.011)$, and occupation $(\mathrm{p}=0.001)$. However, it did not confirm an association between alcohol consumption and age, sex, and level of education. The associations also indicated that females were $43.0 \%$ less likely to consume alcoholic beverage than males. Furthermore, individual within the ages of 20-25 years and 26-30 years were 2 times whiles those within 31-35 years age group were 4 times more likely to consume alcohol than individual within the ages of 15-19. Youth with primary, JHS/Middle, Secondary and Tertiary education were $62.0 \%$, $67.0 \%, 81.0 \%$ and $62.0 \%$ respectively less likely to consume alcohol than individual with no education. Also, traders $(26.0 \%)$, artisans $(36.0 \%)$ and students $(75.0 \%)$ were less likely to consume alcoholic drinks than unemployed individuals. Traditional worshippers were 9.1 times more likely whiles Muslims were $87.0 \%$ less likely to consume alcohol than Christians (Table 3).

Table 3. Associations between alcohol consumption and background characteristics.

\begin{tabular}{|c|c|c|c|c|c|c|}
\hline \multirow{2}{*}{ Attribute } & \multirow{2}{*}{ Current alcohol consumers $\mathrm{N}=137(\%)$} & \multicolumn{2}{|c|}{ Pearson chi- Square } & \multirow{2}{*}{$\mathrm{OR}^{1}(95 \% \mathrm{CI})$} & \multirow[b]{2}{*}{ p-value } & \multirow{2}{*}{$\mathrm{OR}^{2}(95 \% \mathrm{CI})$} \\
\hline & & Chi - Square & p - Value & & & \\
\hline \multicolumn{7}{|l|}{ Sex } \\
\hline Male & $101(73.72)$ & \multirow{3}{*}{5.33} & \multirow{3}{*}{0.02} & - & \multirow{3}{*}{0.113} & - \\
\hline Female & $36(26.28)$ & & & $0.57(0.35-0.92)$ & & $0.76(0.42-1.36)$ \\
\hline \multicolumn{4}{|l|}{ Age (years) } & & & \\
\hline $15-19$ & $29(21.17)$ & \multirow{4}{*}{12.20} & \multirow{4}{*}{0.01} & - & \multirow{4}{*}{0.317} & - \\
\hline $20-25$ & $62(45.26)$ & & & $1.58(0.91-2.73)$ & & $1.49(0.75-2.96)$ \\
\hline $26-30$ & $31(22.63)$ & & & $2.26(1.38-5.51)$ & & $0.98(0.38-2.55)$ \\
\hline $31-35$ & $15(10.95)$ & & & $3.56(1.40-9.09)$ & & $1.14(0.26-5.02)$ \\
\hline \multicolumn{7}{|l|}{ Education level } \\
\hline No education & $19(13.87)$ & \multirow{6}{*}{4.93} & \multirow{6}{*}{0.03} & - & & - \\
\hline Primary & $19(13.87)$ & & & $0.38(0.16-1.07)$ & \multirow{5}{*}{0.723} & $0.36(0.094-1.38)$ \\
\hline Middle/JSS & $39(28.47)$ & & & $0.33(0.1-0.83)$ & & $0.56(0.17-1.86)$ \\
\hline Secondary & $31(22.63)$ & & & $0.19(0.07-0.49)$ & & $0.40(0.11-1.32)$ \\
\hline Tertiary & $29(21.17)$ & & & $0.38(0.15-1.00)$ & & $0.90(0.24-3.34)$ \\
\hline \multicolumn{4}{|l|}{ Marital status } & & & \\
\hline Married & $37(27.01)$ & \multirow{3}{*}{7.52} & \multirow{3}{*}{0.07} & - & \multirow{3}{*}{0.122} & - \\
\hline Unmarried & $100(72.99)$ & & & $0.45(0.26-0.81)$ & & $0.78(0.30-1.95)$ \\
\hline \multicolumn{4}{|l|}{ Religion } & & & \\
\hline Christian & $105(76.64)$ & \multirow{4}{*}{6.05} & \multirow{4}{*}{0.02} & - & \multirow{4}{*}{0.011} & - \\
\hline Muslim & $28(20.44)$ & & & $0.13(0.05-0.383)$ & & $0.15(0.05-0.45)$ \\
\hline Traditionalist & $4(2.92)$ & & & $9.07(3.08-26.65)$ & & $4.57(1.37-15.22)$ \\
\hline \multicolumn{4}{|l|}{ Occupation } & & & \\
\hline Unemployed & $33(24.09)$ & \multirow{4}{*}{19.36} & \multirow{4}{*}{0.000} & - & \multirow{4}{*}{0.001} & - \\
\hline Trader & $31(22.63)$ & & & $0.74(0.36-1.55)$ & & $0.75(0.33-1.70)$ \\
\hline Artisan & $24(17.52)$ & & & $0.64(0.30-1.387)$ & & $0.71(0.30-1.66)$ \\
\hline Student & $29(21.17)$ & & & $0.25(0.12-0.49)$ & & $0.30(0.13-0.68)$ \\
\hline
\end{tabular}

\section{Discussion}

Data was collected from 316 respondents aged 15-35 years. Males (66.7\%) who participated in this study were almost twice the number of females $(33.3 \%)$. This was due to the fact that most females were unwilling to disclose their alcohol use possibly because society frowns on females who consume alcohol. This gender distribution is not surprising because it is consistent with previous studies conducted by [ 1 \& 23], whose study also reveals more males participation than females. Most of the respondents who consume alcohol were in their active age (20-25) which accounts for approximately $45 \%$ and the least was recorded among the age group of 31-35. This indicates that alcohol consumption decreases with increasing age, and this finding is also supported by the result of Ghana Demographic and Health Survey [8].

The findings indicate that the prevalence of alcohol consumption among the youth in Tokorni-Hohoe was $43 \%$.
This prevalence is higher than a national survey conducted in Ghana with results indicated $25 \%$ prevalence of alcohol consumption among the youth in Ghana [7]. The significant difference can be attributed to unrestricted access or increase number of drinking bars in the community making alcoholic beverage easily accessibility to the youth therefore increasing alcohol consumption.

Majority of males (73.7\%) are currently consuming alcohol while the number of females' currently consuming alcohol is $26.3 \%$. This findings is in line with a study conducted to know the prevalence of psychoactive substance use among the youth, where their findings also indicated that males $(67 \%)$ were consuming alcohol whiles $(33 \%)$ females were consuming alcohol [23]. The reason may be due to gender difference because society encourage males' alcohol consumption but not female alcohol consumption.

Findings on how frequent respondents consume alcohol indicate that more males consumed alcohol on a typical day than their female counterparts. Again, more males were found to consume alcohol within the preceding week than 
females. This finding is in line with a study conducted by [8 $\&$ 24] who found that males consume more alcohol on a typical day or weekly than females. This could be that, males are more likely to be stressed up after a hard physical day's work, so they result in drinking alcohol to release their stress.

The result indicated that most of the youth consume more alcohol weekly, followed by monthly, daily and yearly respectively. This finding is similar to a study conducted in Nigeria to know some factors on alcohol use and abuse among University students, and their findings show that alcohol was mostly consumed daily and weekly [20].

Alcoholic beverages that were mostly consumed by the youth were in the form of beer, wine and spirit respectively. This is an indication that most of the youth are at risk of developing lung cancer because a review of epidemiology evidence on alcohol and lung cancer shows that individuals who consume beer are at higher risk of developing lung cancer [25]. This finding also agrees with [12] survey in Gambia among the youth, which found out that beer was mostly used by the youth, followed by wine and spirit. This could be that, beer is one of the alcoholic beverages that are mostly advertised on social media and the youth out of curiosity want to know how it tastes, therefore increasing it consumption.

There was significant association between alcohol consumption and all the socio-demographic factors except marital status. Surprisingly, the likelihood of alcohol consumption among females was higher as compared to males. This is probably due to women empowerment where females are now empowered to compete with their male counterpart. However, this finding is not consistent with a study conducted by [26] who found that males are more likely to consume alcoholic beverage than females.

There was an association between alcohol consumption and age. Alcohol consumption was found to be highest among the age group of 20-25 and lowest within the age group of 31-35. This result indicated that alcohol consumption decreases with increasing age. This means that young individuals are more likely to consume alcohol than adults. On the contrary, the finding disagrees with [23 \& 27] who found that alcohol consumption increases with increasing age. The difference may be due to the fact that their study was conducted in their various countries therefore having a larger sample size, whiles this study was only focused on one community.

Alcohol consumption was significantly associated with educational level. The highest alcohol consumption was found among JHS/Middle and the least was recorded among primary students and individuals with no formal education. This indicates that the individuals with higher education are more likely to consume alcohol than those without formal education. This finding is supported by a previous study conducted by [8].

With regard to marital status, unmarried individuals were more likely to consume alcohol than married women. Similarly, these findings is consistent with national survey on substance use among the youth in Ghana [7].

There was a strong association between alcohol consumption and religion. Muslims were less likely to consume alcohol than Christians or a traditionalist. This is because the doctrine of Muslims prohibits the use of alcohol in any of their activities whiles Christians and Traditional Worshippers use alcohol in most of their activities such as weddings, funerals and pouring libation. This is not supported by a study conducted by [28] and the disparities may be due to differences in environment.

The results indicate that employed individuals were more likely to consume alcohol than unemployed individuals. This may be due to the fact that employed individual can afford most of the alcoholic beverage so they drink it whenever they feel like drinking alcohol. However, when further multiple regression analysis was done, there was strong association between alcohol consumption and religion, and occupation but it did not confirm the association between alcohol consumption and age, sex, marital status and educational level. This was due to confounding factors that were not accounted for in the study. Out of the listed factors that influence the youth to consume alcohol, almost three-fourth of the respondents attributed alcohol consumption to peer influence, followed by advertisement and easy availability or accessibility. Others attributed alcohol consumption to social networking, parental influence and curiosity respectively. These findings conform to a study conducted by [29] also found that peer influence is the major factor that influences alcohol consumption. This result indicates that the youth are more prone to peer pressure, and for them to be accepted among their peers, they also have to consume alcohol to please them. This increases the likelihood of alcohol consumption among the youth whose peers are drunkards.

Responses from the respondents indicate that most of the youth consume alcohol to have fun, followed by using it as an appetizer, to relax, to cope with stress, to satisfy partner, imitating role model and unemployment was the least factor. This findings were consistent with a study conducted [1] who also found similar reasons associated with substance use in secondary school student.

Frequency distribution of how people feel when they are able to consume alcohol shows that majority of the respondents feel matured when they drink alcohol, followed by feeling happy and feeling richer than peers. Others feel brave, failure, and prosperous when they drink alcohol. This feeling only lasts for a short period of time considering its chronic health effects on the youth.

\section{Conclusion}

Generally, both males and females were found to consume alcohol; however females were less likely to consume alcohol than males. Beer was the commonest alcoholic beverage consume by the youth. Most of the respondents revealed that peer influence is the major factor that influences alcohol consumption. Alcohol use was mostly attributed to having fun but these feelings are ephemeral, considering its chronic effect on the youth. 


\section{Recommendations}

- Central Government and policy makers at the local level should enact policies to restrict the sales of alcohol to the youth and also limit ages that have access to alcohol.

- The DHMT should incorporate campaigns against alcohol both in-school and out-of-school programmes, to mitigate the use of alcohol among the youth if not total abstinence.

- Health promoters should include negative effects of alcohol consumption in their health messages to sensitize the youth on the harmful effects of alcohol.

- Parents should also monitor their children's behaviour to reduce the likelihood of their peers introducing them to alcohol consumption.

- Researchers should conduct similar studies in the Hohoe Municipality in order to know the true prevalence of alcohol among the youth in the Municipality.

- Further, researchers should also conduct studies to determine the prevalence of lung cancer among the youth in the community.

\section{References}

[1] Oshodi, O. Y., Aina, O. F., \& Onajole, A. T. (2010). Substance use among secondary school students in an urban setting in Nigeria: prevalence and associated factors. African Journal of Psychiatry, 13 (1).

[2] Retrieved from http://www.ajol.info/index.php/ajpsy/article/view/53430

[3] Awosusi, A. O \& Adegboyega, J. F (2013). Knowledge of Health Effects and Substance Use among Students of Tertiary Institutions in Southwestern, Nigeria. Journal of Education and Practice. Vol. 4, No. 23, 2013.

[4] Barry, A. E., Johnson, E., Rabre, A., Darville, G., Donovan, K. M., \& Efunbumi, O (2015). Underage access to online alcohol marketing content: a YouTube case study. Alcohol and alcoholism, 50 (1), 89-94.

[5] Frimpong-Mansoh, R. P. (2013). Factors Influencing Alcohol Consumption Among Adult Residents of Tema, Community One in the Greater Accra Region. University of Ghana. Retrieved from http://ugspace.ug.edu.gh/handle/123456789/5896.

[6] Hemphill, S. A., Heerde, J. A., Herrenkohl, T. I., Patton, G. C., Toumbourou, J. W., \& Catalano, R. F. (2011). Risk and protective factors for adolescent substance use in Washington State, the United States and Victoria, Australia: a longitudinal study. Journal of Adolescent Health, 49 (3), 312-320.

[7] National Statistical Office (2005). The cigarette smoking and alcoholic drinking behavior survey. National Statistical Office, 2005 (in Thai).

[8] Dennis-Antwi, J, Sam, A. \& Asare, J. B \& Twene, R. (2003). A National Survey on Prevalence and Social consequences of substance use among second cycle and out of school youth in Ghana. Ministry of health/Ghana health service World health organization. Ghana.

[9] GSS, G., \& Macro, I. C. F. (2009). Ghana demographic and health survey 2008. Accra, Ghana: Ghana Statistical Service, Ghana Health Service, and ICF Macro.

[10] Luginaah, I., \& Dakubo, C. (2003). Consumption and impacts of local brewed alcohol (akpeteshie) in the Upper West Region of Ghana: a public health tragedy. Social Science \& Medicine, 57 (9), 1747-1760.

[11] Adu-Mireku, S. (2003). The prevalence of alcohol, cigarette, and marijuana use among Ghanaian senior secondary students in an urban setting. Journal of Ethnicity in Substance Abuse, 2 (1), 53-65.

[12] Odejide, A. O. (2006). Status of drug use/abuse in Africa: A review. International Journal of Mental Health and Addiction, $4(2), 87-102$.

[13] World Health Organization (2004). Global status report on alcohol 2004. Available from:

http://www.who.int/substance abuse/publications/global_statu s_report_2004_overview.pdf.

[14] Muula, A. S., Kazembe, L. N., Rudatsikira, E., \& Siziya, S. (2008). Suicidal ideation and associated factors among inschool adolescents in Zambia. Tanzania Journal of Health Research, 9 (3), 202-206.

[15] World Health Organization (2011). Global status report on Alcohol and Health. Geneva. Retrieve from (http://www.who.int/ msbgruprofiles/).

[16] World Health Organization (2013). Facts and Figures. Available at: http://www.who.int/substance_abuse/facts/en/.

[17] Bruce, G. F, Leslie, J. F, Jody, L., and Mandy, R. (2012). Religiosity And Alcohol Avoidance: A Study among Canadian Baptist Youth. Vol 11. No 1. Canada.

[18] Lamptey, J. J. (2006). Socio-demographic characteristics of substance abusers admitted to a private specialist clinic. Ghana Medical Journal, 39 (1), 2-7.

[19] Marmorstein, N. R., Iacono, W. G., \& Malone, S. M. (2010). Longitudinal associations between depression and substance dependence from adolescence through early adulthood. Drug and Alcohol Dependence, 107 (2), 154-160.

[20] Chikere, E. I., \& Mayowa, M. O. (2011). Prevalence and perceived health effect of alcohol use among male undergraduate students in Owerri, South-East Nigeria: a descriptive crosssectional study. BMC Public Health, 11 (1), 118.

[21] Onongha, G. I (2012). The Influence of some Factors on Alcohol Use and Abuse among Education Students of Osun State University, Nigeria. International Journal of Humanities and Social Science. Vol. 2 No. 11.

[22] Appo, D., \& Härtel, C. E. (2003). Questioning management paradigms that deal with Aboriginal development programs in Australia. Asia Pacific Journal of Human Resources, 41 (1), $36-50$.

[23] George W. Snedecor and William G. Cochran. (1989). Statistical Methods, 8th Edition; Iowa State University Press. Xix +491 pp.

[24] Kanyoni, M., Gishoma, D., \& Ndahindwa, V. (2015). Prevalence of psychoactive substance use among youth in Rwanda. BMC Research Notes, 8 (1), 190. 
[25] Anderson, P., \& Baumberg, B. (2008). Alcohol in Europe. London: Institute of Alcohol Studies, 2006. A Public Health Perspective.

[26] Bandera, E. V., Freudenheim, J. L., and Vena, J. E (2001). Alcohol Consumption and lung Cancer: $A$ Review of the Epidemiologic Evidence, Vol. 10, 813-821, August 2001. Cancer Epidemiology. Biomarkers \& Prevention.

[27] Simons-Morton, B. G., Farhat, T., Ter Bogt, T. F., Hublet, A., Kuntsche, E., Gabhainn, S. N., others. (2009). Gender specific trends in alcohol use: cross-cultural comparisons from 1998 to 2006 in 24 countries and regions. International Journal of Public Health, 54 (2), 199-208.
[28] Chen, K.-T., Chen, C.-J., Fagot-Campagna, A., \& Narayan, K. M. (2001). Tobacco, betel quid, alcohol, and illicit drug use among 13-to 35-year-olds in I-Lan, rural Taiwan: prevalence and risk factors. American Journal of Public Health, 91 (7), 1130.

[29] Karick, H., \& Ojiji, O. (2005). Akanidomo J. Ibanga, Adebola V. Adetula, Zubairu Dagona. Alcohol, Gender and Drinking Problems, 143. 